\title{
Risk factors associated with the presence and severity of food insecurity in rural Honduras
}

\author{
Maureen E Ben-Davies ${ }^{1,2, *}$, Alan Kinlaw ${ }^{3}$, Yaniré Estrada del Campo ${ }^{4}$, \\ Margaret E Bentley ${ }^{4}$ and Anna Maria Siega-Riz ${ }^{3,4}$ \\ 'Department of Pediatrics, Division of General Pediatrics and Adolescent Medicine, The University of North \\ Carolina at Chapel Hill School of Medicine, Chapel Hill, NC, USA: ${ }^{2}$ Cecil G. Sheps Center for Health Services \\ Research, The University of North Carolina at Chapel Hill, 725 Martin Luther King Blvd, CB 7590, Chapel Hill, \\ NC 27599, USA: ${ }^{3}$ Department of Epidemiology, Gillings School of Global Public Health, The University of \\ North Carolina at Chapel Hill, Chapel Hill, NC, USA: ${ }^{4}$ Department of Nutrition, Gillings School of Global \\ Public Health, The University of North Carolina at Chapel Hill, Chapel Hill, NC, USA
}

Submitted 9 November 2012: Final revision received 4 June 2013: Accepted 13 June 2013: First published online 5 August 2013

\begin{abstract}
Objective: To identify factors associated with the presence and severity of food insecurity among a sample of Honduran caregivers of young children.

Design: Cross-sectional study in which the dependent variable, household food insecurity, was measured using a fourteen-item questionnaire developed and validated in a population of similar cultural context. A predictive modelling strategy used backwards elimination in logistic regression and multinomial logit regression models to compute odds ratios and 95\% confidence intervals for food insecurity.

Setting: Rural Honduras in the department of Intibucá, between March and April 2009.

Subjects: Two-hundred and ninety-eight Honduran caregivers of children aged 6-18 months.

Results: Ninety-three per cent of households were classified as having some degree of food insecurity (mild, moderate or severe). After controlling for caregiver age and marital status, compared with caregivers with more than primary-school education, those with less than primary-school education had 3.47 (95\% CI 1.34, 8.99) times the odds of severe food insecurity and $2 \cdot 29$ (95\% CI $1 \cdot 00,5 \cdot 25)$ times the odds of moderate food insecurity. Our results also found that child anthropometric status was not associated with the presence or severity of food insecurity.

Conclusions: These results show that among the sociodemographic factors assessed, food insecurity in rural Honduras is associated with maternal education. Understanding key factors associated with food insecurity that are unique to Honduras can inform the design of interventions to effectively mitigate the negative impact of food insecurity on children.
\end{abstract}

Keywords

Food insecurity

Risk factors

Honduras

Education
Food insecurity - defined at the household level as having limited access to food or limited availability of food to promote a healthy and productive life - negatively impacts human capital and compromises the development of fragile economies ${ }^{(1,2)}$. The deleterious effect of household food insecurity on children's health and well-being has been well established ${ }^{(3-5)}$. Particularly in developing countries, children who grow up in food-insecure households are more likely to have high rates of school absenteeism, delayed early language development and have worse morbidity in general than children who live in food-secure homes ${ }^{(5-8)}$.

In Honduras, a lower-middle-income country where $60 \%$ of the population lives on less than \$US 2 per day ${ }^{(9)}$, malnutrition due to food insecurity poses a substantial threat for children. Fewer social safety nets and global food price fluctuations may negatively impact individual access to food ${ }^{(10)}$. In order to address the problem of decreased access to food and limited availability of food in resource-limited contexts, identifying those at highest risk for food insecurity is critical for programme planning ${ }^{(11)}$. Research in other developing countries has identified household size ${ }^{(12)}$, maternal age ${ }^{(13)}$ and educational status ${ }^{(13)}$, as well as the presence of social support, as being important determinants of food insecurity ${ }^{(14)}$. Information on proven risk factors can aid in targeting programmes specifically aimed at reducing household food insecurity within unique socio-cultural contexts. 
While patterns do exist for the importance of specific characteristics within other populations, the factors associated with food insecurity may be unique to each context. Research identifying the factors associated with food insecurity in Honduras is limited ${ }^{(15,16)}$.

In regions with limited resources, child anthropometrics may be used to assess household food security ${ }^{(17)}$. Such indicators may be used not only for effective targeting of food programmes but also in determining whether an intervention has been successful ${ }^{(18,19)}$. Despite high rates of poverty in countries of Latin America, there is lower prevalence of underweight and stunting than in other poor regions of the world ${ }^{(20,21)}$. There has been limited research examining the association between food insecurity and growth parameters during early childhood in Honduras. A study conducted among school-aged children in Honduras found that food insecurity was associated with stunting ${ }^{(16)}$. There have been no similar examinations of the influence of limited household food supply on the growth parameters of infants or young toddlers in Honduras.

The specific objectives of the present study were to determine the factors, specifically maternal socio-economic and demographic characteristics, that are associated with food insecurity using a cross-sectional study design as well as to determine whether child anthropometrics are associated with caregiver food security status and severity in the rural department of Intibucá, Honduras.

\section{Methods}

\section{Study area and study population}

The site of the study was the Department (state) of Intibucá in rural Honduras. Of the nearly 8 million Honduran residents, $51 \%$ live in rural areas and lead mainly a subsistence lifestyle ${ }^{(9,22)}$. Intibucá occupies a land area of $536 \cdot 74 \mathrm{~km}^{2}$ with an estimated population of 179862 people and has several main agricultural products, including corn, sorghum and beans, with the harvest arriving between the months of May and October ${ }^{(23)}$. The present data were collected prior to the harvest season and food scarcity was presumably more prevalent. Intibucá is one of the five poorest states in Honduras, with over $60 \%$ of its inhabitants living on less than \$US 2 per day ${ }^{(24)}$. The burden of child malnutrition is high: the prevalence of stunting and wasting among children under 5 years old is $25 \%$ and $20 \%$, respectively, according to national surveys ${ }^{(25)}$.

\section{Study design}

The present study used baseline, cross-sectional data collected from a sample of 298 adult caregivers enrolled in the Mejorando la Alimentaciòn de los Niños en Intibucá (MANI) project, a community-based nutrition education and supplementation trial (Clinical Trials No. NCT01312987) conducted to assess the efficacy of a lipid-based nutritional supplement in improving nutritional status in rural Honduran infants 6-18 months of age. The sample was recruited from eighteen communities within Intibucá located in three municipalities (Santa Lucia, Magdalena and San Antonio), chosen because of their existing relationship with a collaborating non-profit organization, Shoulder to Shoulder. Mother-child dyads were recruited by convenience sampling for the study by radio advertisements and distribution of flyers/posters at community venues as well as door-to-door distribution of flyers.

Caregivers were invited to enrol in the study if they were the primary caregiver of an infant 6-18 months of age, if they were 16 years of age or older, and if they had no plans to move from the study region. Caregivers were excluded from the study if they had infants with medical conditions including congenital abnormalities, mental retardation, severe physical handicap or allergy to peanuts. Infants with weight-for-length $Z$-score below -2 using the 2006 WHO growth reference parameters were excluded and referred for close supervision by a qualified healthcare facility. Infants who were allergic to peanuts, a major component of the lipid-based nutritional supplement used in the trial, were also excluded.

The study was conducted according to the guidelines laid down in the Declaration of Helsinki and all procedures involving human subjects were approved by the University of North Carolina Bio-medical Institutional Review Board. Verbal informed consent was witnessed and formally recorded for all subjects.

\section{Data collection}

Data were gathered for each caregiver at their enrolment into the study between March and April 2009, corresponding to a time prior to the harvest season, by means of an in-person standardized questionnaire at each study site. Household food security status over the last month was assessed with a fourteen-item instrument developed and validated within the context of an urban Latin American community ${ }^{(25,26)}$. The present study is the first to use this instrument in a rural population. The instrument was verbally administered in Spanish by a trained data collector for the project during an in-person interview. The instrument used in the study is similar to the eighteen-item instrument used by the US Department of Agriculture in assessment of food insecurity in US households, in which participants respond to questions around food availability for adults and children in the home. During development of this instrument in prior research, the severity of food insecurity was based upon the respondent's answers to specific questions in the instrument (Table 1). Food insecurity was categorized into three levels: (i) mild food insecurity (families feeling uncertain and worry about ability to satisfy food needs for the family and adults' diet quality reduced); (ii) moderate food insecurity (adults' diet quantity is compromised, but the meal frequency and food patterns are sustained, and child diet quality is reduced); and (iii) severe food 
insecurity (child diet quantity is reduced, eating patterns are interrupted, and adults carry out shameful and socially unacceptable coping behaviours to obtain food) ${ }^{(26)}$.

\section{Socio-economic and demographic characteristics}

We assessed the relationship of the caregiver to the child, as well as demographic characteristics of the caregiver including age, ever attended school, total number of years attending school, highest level reached in school, parity, the age at initial parity and total number of children. We also identified the primary provider of the household's monetary resources for food (e.g. father, mother, grandparent or spouse), the caregiver's employment status and household structure (specifically the number of adults in the home and the total number of people, including the presence of non-biological children). In addition, marital status was assessed by interviewers who asked each participant the following question: 'What is your marital status?' (¿Cuál es su estado civil?). The provided response options were 'single', 'married', 'not married/living together', 'divorced/separated' or 'widowed' (soltera/o, casada/o, convive (no está casada/o), divorciada/o o separada/o, viuda/o).

\section{Child antbropometric measurement}

As part of the nutritional supplementation intervention, trained research staff gathered anthropometric data for each infant. Infant weight and height were assessed without clothing or wet diapers, using an electronic scale (SECA) to the nearest $10 \mathrm{~g}$ for weight and an infantometer (SECA) to the nearest $0 \cdot 10 \mathrm{~cm}$ for length.

\section{Statistical analysis}

To develop informative coding structures for each potential covariate representing demographic information, univariable logistic regression was used to assess linearity of estimated odds of food insecurity in the study population. For variables that violated the linearity assumption, categorical variable functions were created for use in multivariable models.

In bivariate analysis, $\chi^{2}$ tests (for categorical variables) and ANOVA (for continuous variables) were used to examine statistical associations between food insecurity and each potential covariate using an a priori $\alpha$ level of 0.05 (Tables 2 and 3).

For the purpose of multivariable modelling, after its distribution as a continuous/discrete variable was considered in univariable logistic regression, caregiver's age was categorized into a three-level variable ( $\leq 22,23-30$ and $\geq 31$ years of age). Based on the number of years reported for attending school, caregiver's level of education was treated as a binary variable (completion of education beyond primary school $v$. no more than primary-school education). Marital status was treated as a three-level nominal variable with categories of married, cohabiting (i.e. not married but living together) and a third category comprising single status, divorced, separated and widowed.
In exploratory analysis, 7\% of surveyed households were classified as food secure; these households were combined with those classified as having mild food insecurity (13\%) since these two groups represented the lowest levels of food insecurity and their demographic characteristics were not different (data not shown). Child length-for-age, weight-for-age and weight-for-length $Z$-scores were calculated using available anthropometric data on enrolled children according to the WHO Child Growth Standards ${ }^{(27)}$.

To begin assessment of which measured covariates were predictors of food insecurity, a binary variable was created for food insecurity based on the original fourlevel variable, grouping 'food security' and 'mild food security' as the reference outcome and 'moderate food insecurity' together with 'severe food insecurity' as the index outcome. Backwards elimination using multivariable logistic regression was employed to examine the goodness-of-fit contributed to the logistic model by each potential covariate and each hypothesized interaction term. Interaction terms included age of caregiver by level of education and age of caregiver by number of live children. Goodness-of-fit was evaluated using a likelihood ratio test with an a priori $\alpha$ level of $0 \cdot 10$ for elimination of interaction terms and potential covariates from the final logistic model.

To account for the nominal nature of the outcome categories and to relax the assumptions incurred by grouping four variable levels into two, the covariates associated with food insecurity under the final logistic model were applied to a multinomial model characterized by a three-level food insecurity outcome variable with the following levels: 'food security/mild food insecurity', 'moderate food insecurity' and 'severe food insecurity'. Because the proportional odds assumption was not appropriate in the context of the three-level food insecurity outcome variable, a multinomial logit model was used to estimate the odds of moderate food insecurity or severe food insecurity, relative to none/mild food insecurity, along with 95\% confidence intervals for each contrast. Simulation profiles from the multinomial logit model were processed to reflect predicted odds ratios and 95\% confidence intervals for all potential covariate pattern combinations. All statistical analyses were carried out using the FREQ, GENMOD and LOGISTIC procedures within the SAS statistical software package version 9·2. Computations pertaining to child growth parameters were performed with WHO Anthro software version $3 \cdot 2 \cdot 2$.

\section{Results}

\section{Descriptive characteristics}

Nearly all respondents (94\%) were mothers of the children enrolled in the study. At baseline, median caregiver age was 25 years (25th, 75th percentile (P25, P75): 21, 32 years). 
The participants had a median of two biological children (P25, P75: 1, 4) and 32\% of participants reported that other non-biological children lived in their home. The median size of the household was seven (P25, P75: 5, 9) persons. One-third were single/divorced/separated/widowed, 20\% were married and $48 \%$ were unmarried but living together. While the majority (94\%) reported that they had attended school, the median number of years of schooling was 6 years (P25, P75: 3, 6 years). Only 10\% of the respondents reported being employed.

Out of 300 participants in the original sample, two were eliminated from analysis because they were ineligible based on age at the time of recruitment. Characteristics of the sample are described in Table 1. One hundred and eleven respondents (37\%) were identified with severe food insecurity; 126 respondents (42\%) with moderate food insecurity, forty participants (13\%) with mild food insecurity and twenty-one (7\%) with food security. Using the categorical three-level food insecurity variable, Table 2 shows the distribution of food insecurity by demographic characteristics of the sample.

In bivariate analysis, a larger proportion (38\%) of caregivers who had severe food insecurity were older ( $\geq 31$ years old) than caregivers classified as having none/ mild food insecurity (21\%) or moderate food insecurity (29\%), but these differences were not statistically significant based on a $\chi^{2}$ test using an a priori $\alpha$ level of $0 \cdot 05$. The mean number of children was lower for food-secure/ mildly food-insecure caregivers (2.4) than for moderately $(3 \cdot 1)$ or severely $(3 \cdot 7)$ food-insecure caregivers and there were also fewer people living in the home for those who were classified as being food secure $(6 \cdot 4$ people) than those who were moderately or severely food insecure
(6.9 and $7 \cdot 3$ people, respectively), not a statistically significant difference (data not shown). Food insecurity was also associated with the primary caregiver's maximum educational level ( $\chi^{2} P=0 \cdot 04$, Table 2$)$. Caregivers with none or mild food insecurity had a higher prevalence of having completed education beyond primary school (24\%) than those with moderate $(11 \%)$ or severe food security $\left(8 \% ; \chi^{2} P=0 \cdot 02\right.$, data not shown).

There was no evidence of an association between food security and the age at which the mother gave birth to her first child (Table 2). A larger proportion of caregivers from food-secure/mildly food-insecure households reported receiving monetary support from grandparents than those who lived in households with severe food insecurity (16\% v. 7\%); however, this difference was not statistically significant using an a priori $\alpha$ level of 0.05 .

There was no association between food security and anthropometric Z-scores (Table 3).

\section{Multivariate results}

Following backwards elimination using multivariable logistic regression and an a priori $\alpha$ level of $0 \cdot 10$, the covariates that were independently associated with moderate and severe food insecurity were caregiver's age, level of education and marital status (data not shown). In the multinomial logit model, these three covariates exhibited attenuated independent associations with food insecurity; however, only the association between caregiver education and food insecurity was precise enough to have a $95 \%$ confidence interval exclusive of a null association (Table 4).

Controlling for age of the child's caregiver and marital status, caregivers with education at or below primaryschool level lived in households associated with severe

Table 1 Food insecurity questionnaire items and the frequency of affirmative participant responses* at baseline (with respect to the previous month); caregivers ( $n$ 298) of children aged 6-18 months, Intibucá, rural Honduras, March-April 2009

\begin{tabular}{|c|c|c|}
\hline \multirow[b]{2}{*}{ Questionnaire item } & \multicolumn{2}{|c|}{ Affirmative ( $n$ 298) } \\
\hline & $n$ & $\%$ \\
\hline Have you worried that in your home there was not enough food and you could not obtain more?t & 215 & 72 \\
\hline Did you or any adult in your home have to limit the variety of food because of lack of resources? + & 222 & 74 \\
\hline $\begin{array}{l}\text { Did you or any adult in your home have to eat the same food for several days in a row because you didn't have food to } \\
\text { prepare another or different meal? } t\end{array}$ & 241 & 81 \\
\hline Did you have to serve less food because there weren't resources to obtain enough food?t & 229 & 77 \\
\hline Because there was not enough food at home, were you unable to prepare one of the meals of the day? $\neq$ & 151 & 51 \\
\hline Did you or any adult in your home have to skip one of the meals of the day because there was not enough food? & 132 & 44 \\
\hline Did you or any adult in your home have to go to sleep without eating because there was not enough food at home? & 41 & 14 \\
\hline Did you or any adult in your home have to go a whole day without eating because there was not enough food?§ & 13 & 4 \\
\hline Did you have to stop giving the children the food they should have because you couldn't obtain it? $\ddagger$ & 158 & 53 \\
\hline Because there was not enough food at home, did you have to serve less food to the children? $\ddagger$ & 187 & 63 \\
\hline Did any of the children have to skip one of the meals of the day because there was not enough food at home?§ & 102 & 34 \\
\hline Did any of the children have to go to sleep without eating because there was not enough food at home?§ & 28 & 9 \\
\hline Did any of the children have to go a whole day without eating because there was not enough food?§ & 6 & 2 \\
\hline In order to have food in your home, did you have to do things that make you feel ashamed? & 24 & 8 \\
\hline
\end{tabular}

`For each item, responses of 'many times' or 'sometimes' were considered affirmative and responses of 'never' were considered as negative.

tAmong those not otherwise classified as having severe or moderate food insecurity, affirmative response to any of these items resulted in classification of mild food insecurity.

$\ddagger$ Among those not otherwise classified as having severe food insecurity, affirmative response to any of these items resulted in classification of moderate food insecurity.

$\S$ Regardless of other responses, affirmative response to any of these items resulted in classification of severe food insecurity. 
Table 2 Sociodemographic characteristics of the study population at baseline by food insecurity status; caregivers $(n 298)$ of children aged 6-18 months, Intibucá, rural Honduras, March-April 2009

\begin{tabular}{|c|c|c|c|c|c|c|c|}
\hline & \multicolumn{6}{|c|}{ Food insecurity status } & \multirow[b]{3}{*}{$P$ value } \\
\hline & \multicolumn{2}{|c|}{ None or mild $(n 61)$} & \multicolumn{2}{|c|}{ Moderate $(n 126)$} & \multicolumn{2}{|c|}{ Severe $(n 111)$} & \\
\hline & $n$ & $\%$ & $n$ & $\%$ & $n$ & $\%$ & \\
\hline Interviewee is the mother of participant & & & & & & & 0.25 \\
\hline No & 1 & 2 & 10 & 8 & 7 & 6 & \\
\hline Yes & 60 & 98 & 116 & 92 & 104 & 94 & \\
\hline Interviewee is the child's primary caregiver & & & & & & & 0.58 \\
\hline No & 0 & 0 & 0 & 0 & 1 & 1 & \\
\hline Yes & 61 & 100 & 126 & 100 & 110 & 99 & \\
\hline Age of primary caregiver (years) & & & & & & & $0 \cdot 22$ \\
\hline$\leq 22$ & 23 & 38 & 40 & 32 & 30 & 27 & \\
\hline $23-30$ & 25 & 41 & 50 & 40 & 39 & 35 & \\
\hline$\geq 31$ & 13 & 21 & 36 & 29 & 42 & 38 & \\
\hline Primary caregiver ever attended school & & & & & & & $0 \cdot 19$ \\
\hline No & 1 & 2 & 8 & 6 & 10 & 9 & \\
\hline Yes & 60 & 98 & 118 & 94 & 101 & 91 & \\
\hline Maximum education level of primary caregiver & & & & & & & 0.04 \\
\hline Did not attend school & 1 & 2 & 8 & 6 & 10 & 9 & \\
\hline Primary school (1st-6th grade) & 46 & 75 & 104 & 83 & 93 & 84 & \\
\hline Secondary school (7th-9th grade) & 4 & 7 & 6 & 5 & 3 & 3 & \\
\hline Career/diversified & 9 & 15 & 8 & 6 & 5 & 5 & \\
\hline University & 1 & 2 & 0 & 0 & 0 & 0 & \\
\hline Marital status of primary caregiver & & & & & & & 0.75 \\
\hline Cohabiting & 26 & 43 & 63 & 50 & 54 & 49 & \\
\hline Married & 21 & 34 & 42 & 33 & 33 & 30 & \\
\hline Single/divorced/separated/widowed & 14 & 23 & 21 & 17 & 24 & 22 & \\
\hline Age at first birth of primary caregiver/mother (years) & & & & & & & $0 \cdot 78$ \\
\hline$\leq 22$ & 49 & 80 & 102 & 81 & 94 & 85 & \\
\hline $23-30$ & 11 & 18 & 21 & 17 & 13 & 12 & \\
\hline$\geq 31$ & 1 & 2 & 1 & 1 & 2 & 2 & \\
\hline Missing & 0 & 0 & 2 & 2 & 2 & 2 & \\
\hline Total number of pregnancies & & & & & & & $0 \cdot 16$ \\
\hline 1 & 24 & 39 & 35 & 28 & 30 & 27 & \\
\hline 2 & 14 & 23 & 28 & 22 & 18 & 16 & \\
\hline$\geq 3$ & 23 & 38 & 63 & 50 & 63 & 57 & \\
\hline Total number of live children & & & & & & & $0 \cdot 21$ \\
\hline 1 & 26 & 43 & 39 & 31 & 34 & 31 & \\
\hline 2 & 14 & 23 & 29 & 23 & 20 & 18 & \\
\hline$\geq 3$ & 20 & 33 & 57 & 45 & 57 & 51 & \\
\hline Missing & 1 & 2 & 1 & 1 & 0 & 0 & \\
\hline Number of people living in home & & & & & & & $0 \cdot 20$ \\
\hline$\leq 4$ & 17 & 28 & 24 & 19 & 18 & 16 & \\
\hline $5-8$ & 31 & 51 & 70 & 56 & 55 & 50 & \\
\hline$\geq 9$ & 13 & 21 & 32 & 25 & 38 & 34 & \\
\hline Number of adults living in home & & & & & & & 0.57 \\
\hline$\leq 2$ & 28 & 46 & 60 & 48 & 63 & 57 & \\
\hline $3-5$ & 28 & 46 & 56 & 44 & 39 & 35 & \\
\hline$\geq 6$ & 5 & 8 & 10 & 8 & 9 & 8 & \\
\hline Other people's children live/eat in interviewee's home & & & & & & & 0.42 \\
\hline No & 45 & 74 & 87 & 69 & 71 & 64 & \\
\hline Yes & 16 & 26 & 39 & 31 & 40 & 36 & \\
\hline Provider of money to buy food for household & & & & & & & 0.07 \\
\hline Mother of child & 8 & 13 & 29 & 23 & 22 & 20 & \\
\hline Grandfather/grandmother of child & 10 & 16 & 18 & 14 & 8 & 7 & \\
\hline Father of child/current spouse or partner & 38 & 62 & 71 & 56 & 67 & 60 & \\
\hline Other legal guardian & 1 & 2 & 6 & 5 & 11 & 10 & \\
\hline Other & 4 & 7 & 2 & 2 & 3 & 3 & \\
\hline Primary caregiver was employed at study entry & & & & & & & $0 \cdot 74$ \\
\hline No & 54 & 89 & 113 & 90 & 101 & 91 & \\
\hline Yes & 7 & 11 & 13 & 10 & 9 & 8 & \\
\hline Missing & 0 & 0 & 0 & 0 & 1 & 1 & \\
\hline
\end{tabular}

${ }^{*} P$ values are two-sided and based on Fisher's exact test of table probability for each item.

and, to a lesser extent, moderate food insecurity. Compared with having more than primary-school education, caregivers having no more than primary-school education lived in households with 3.47 (95\% CI 1.34, 8.99) times the odds of severe food insecurity and $2 \cdot 29$ (95\% CI $1 \cdot 00,5 \cdot 25)$ times the odds of moderate food insecurity. 
Table 3 Anthropometric growth characteristics of the study population at baseline by food insecurity status; caregivers ( $n$ 298) of children aged 6-18 months, Intibucá, rural Honduras, March-April 2009

\begin{tabular}{|c|c|c|c|c|c|c|c|}
\hline & \multicolumn{6}{|c|}{ Food insecurity status } & \multirow[b]{3}{*}{$P$ value* } \\
\hline & \multicolumn{2}{|c|}{ None or mild ( $n 61)$} & \multicolumn{2}{|c|}{ Moderate $(n 126)$} & \multicolumn{2}{|c|}{ Severe $(n 111)$} & \\
\hline & Median & P25, P75 & Median & P25, P75 & Median & P25, P75 & \\
\hline Length-for-age $Z$-score of child & -0.48 & $-1 \cdot 39,0 \cdot 16$ & -0.57 & $-1 \cdot 31,0 \cdot 14$ & $-0 \cdot 75$ & $-1 \cdot 53,-0.21$ & 0.42 \\
\hline Weight-for-age $Z$-score of child & -0.25 & $-0.88,0.09$ & -0.42 & $-1 \cdot 02,0.30$ & -0.63 & $-1 \cdot 28,0 \cdot 22$ & 0.24 \\
\hline Weight-for-length Z-score of child & $-0 \cdot 14$ & $-0.66,0.36$ & $-0 \cdot 15$ & $-0.77,0.51$ & $-0 \cdot 21$ & $-1 \cdot 00,0.37$ & $0 \cdot 46$ \\
\hline
\end{tabular}

P25, 25th percentile; P75, 75th percentile.

${ }^{*} P$ values are based on the $F$ test for contrast using one-way ANOVA.

Table 4 Odds ratios for severe and moderate food insecurity compared with none/mild food insecurity based on a multinomial logit model: caregivers (n 298) of children aged 6-18 months, Intibucá, rural Honduras, March-April 2009

\begin{tabular}{|c|c|c|c|c|}
\hline & \multicolumn{2}{|c|}{ Severe $v$. none/mild food insecurity } & \multicolumn{2}{|c|}{ Moderate $v$. none/mild food insecurity } \\
\hline & OR & $95 \% \mathrm{Cl}$ & OR & $95 \% \mathrm{Cl}$ \\
\hline \multicolumn{5}{|l|}{ Age of caregiver (years) ${ }^{*}$} \\
\hline$\leq 22$ & $0 \cdot 68$ & $0 \cdot 31,1 \cdot 48$ & $0 \cdot 80$ & $0 \cdot 38,1 \cdot 67$ \\
\hline 23-30 & $1 \cdot 00$ & Ref. & $1 \cdot 00$ & Ref. \\
\hline$\geq 31$ & $2 \cdot 06$ & $0 \cdot 88,4 \cdot 80$ & $1 \cdot 30$ & $0.57,3.00$ \\
\hline \multicolumn{5}{|l|}{ Level of educationt } \\
\hline Primary school or less & $3 \cdot 47$ & $1.34,8.99$ & $2 \cdot 29$ & $1 \cdot 00,5 \cdot 25$ \\
\hline More than primary school & $1 \cdot 00$ & Ref. & $1 \cdot 00$ & Ref. \\
\hline \multicolumn{5}{|l|}{ Marital status $\ddagger$} \\
\hline Married & $1 \cdot 00$ & Ref. & 1.00 & Ref. \\
\hline Cohabiting & $1 \cdot 85$ & $0 \cdot 84,4 \cdot 06$ & $1 \cdot 40$ & $0 \cdot 66,2 \cdot 98$ \\
\hline Single/divorced/separated/widowed & $1 \cdot 78$ & $0.68,4.62$ & 0.95 & $0 \cdot 37,2 \cdot 41$ \\
\hline
\end{tabular}

Ref., referent category.

*OR are adjusted for main effects for level of education and marital status.

tOR are adjusted for main effects for age of caregiver and marital status.

$\ddagger O R$ are adjusted for main effects for age of caregiver and level of education.

Figure 1 illustrates the range of simulated profiles according to odds ratio estimates computed by the multinomial logit model for the three-level outcome for food insecurity.

\section{Discussion}

Food insecurity exists across diverse geographic settings, both in developed and developing countries. The factors that are associated with food insecurity vary and some may be unique to each particular geographic and socio-cultural setting. In the present study, according to caregiver report on their perceptions of household food availability, food insecurity was very common. We found that maternal educational attainment - specifically if she had completed primary school or not - was associated with moderate and severe food insecurity after controlling for maternal age and marital status. In this rural and impoverished community in Honduras we also found that, contrary to our assumptions, the severity of household food insecurity was not associated with anthropometric measurements among young children.

Aside from these findings, there are limited data on the existence of associations between food insecurity and household/caregiver characteristics within the context of Honduras. Prior research in Honduras has shown that children who live in areas of lower maternal education have increased risk of poor nutritional status ${ }^{(15,28)}$. According to results from a 2006 national survey, over $60 \%$ of Honduran women lacked a secondary education and in areas that had lower levels of maternal education, child nutritional status in terms of height-for-age $Z$-score was compromised ${ }^{(28)}$. However, the present study is the first to our knowledge that describes an inverse relationship between household food insecurity and maternal educational attainment in Honduras.

Women who are able to complete school are able to lower the risk of household food insecurity and improve their financial resources by being better equipped in cognitive skills and self-efficacy which allows them to participate in the formal market economy of their communities ${ }^{(29)}$. According to the most recently available statistics, over $90 \%$ of girls in Intibucá, Honduras have less than a secondary education ${ }^{(28)}$. Improved education for women is a critical target in advancing public health, highlighted by the mandate set forth by the UN Millennium Development Goals to promote universal primary-school education for both boys and girls by the year $2015^{(30)}$. Results from the present study would suggest that policies 
(a)

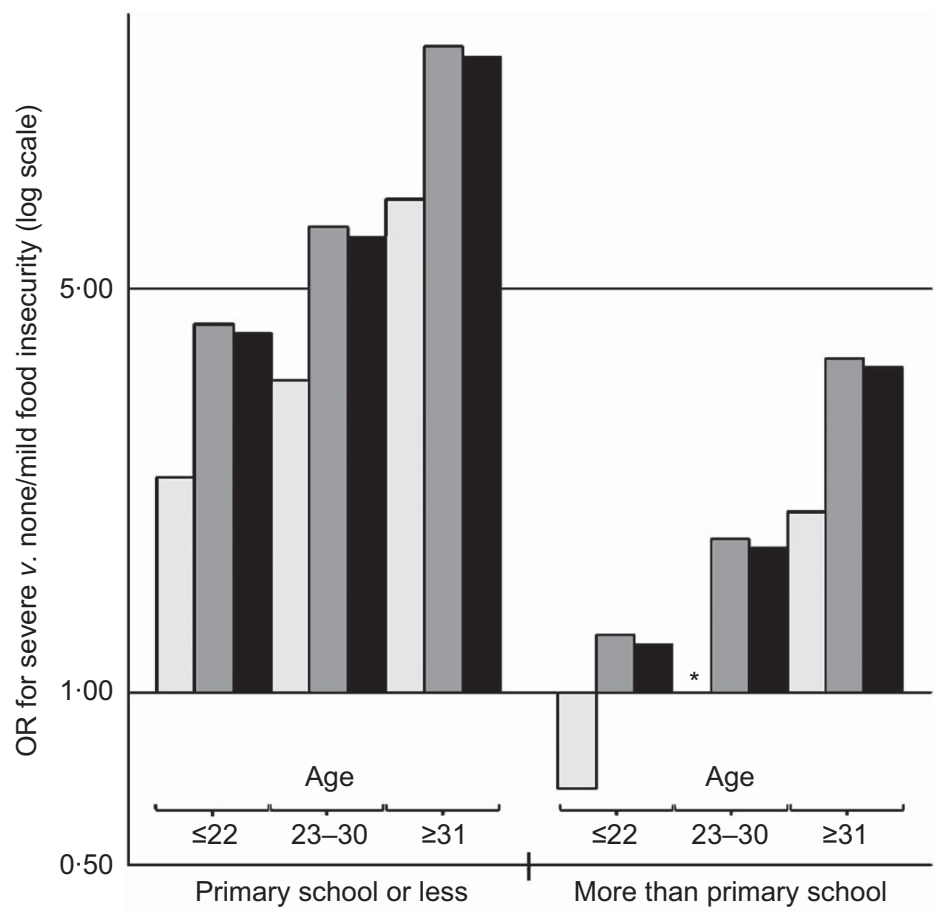

(b)

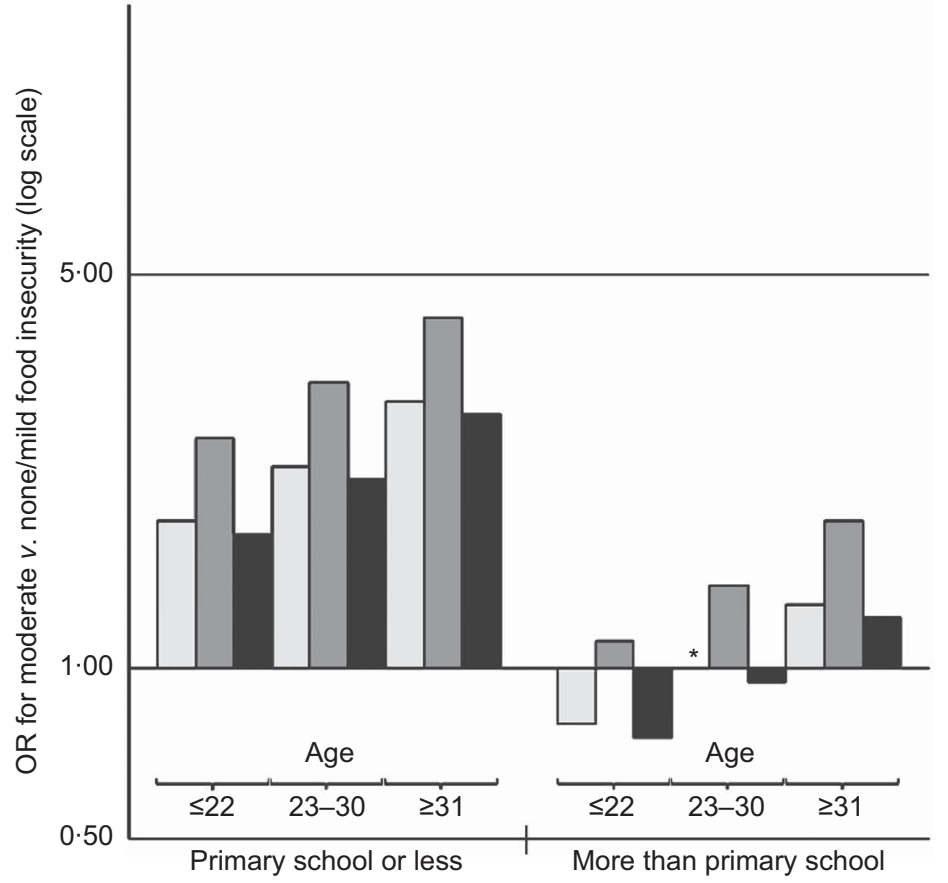

Fig. 1 Predicted odds ratios for severe (a) and moderate (b) food insecurity compared with none or mild food insecurity, based on primary caregiver's level of education, age in years and marital status ( $\square$, married; $\square$, cohabiting; $\square$, single/divorced/separated/ widowed) at baseline; caregivers ( $n$ 298) of children aged 6-18 months, Intibucá, rural Honduras, March-April 2009. *Referent was caregivers aged 23-30 years who had attained more than a primary-school level of education and who were married at baseline

in Honduras directly promoting primary education for young girls would have an impact on the problem of household food security, ultimately improving child health and development.

We also found that other demographic characteristics including marital status, number of children in the home and caregiver age were not significantly associated with the presence and severity of food insecurity. These results differ from other studies in developing countries which have highlighted the importance of such factors on influencing household food security ${ }^{(31-34)}$. For example, female head of household, low household income and older age of the caregiver were found to be associated with food insecurity in one study conducted in Antioquia, 
Colombia ${ }^{(31)}$. Our sampling limits our ability to generalize our findings to other areas of Honduras; however, it is possible that coping strategies to manage food insecurity include dependence on other family members outside the household. In the current study, we did not assess whether caregivers benefited from monetary remittances received from relatives who worked abroad. Cash remittances are known to improve nutritional outcomes among children living in the Latin American region ${ }^{(35)}$. This information may be useful in understanding the degree of importance of these characteristics in alleviating food insecurity despite the existence of other established risk factors. Further research on risk factors for household food insecurity in Honduras is warranted.

In the present study household food insecurity was a common problem, with nearly $93 \%$ having some degree of food insecurity (mild, moderate or severe). Results of a cross-sectional study in 2006 found a $65 \%$ prevalence of food insecurity in an area of Central Honduras ${ }^{(16)}$. Several factors unique to this setting may provide insight into the high prevalence of food insecurity that we observed. The study was conducted in one of the poorest regions of Honduras, where unemployment rates are high and the social safety net is limited. Further, the regional economy is heavily dependent upon agricultural production. This vulnerability may have been illustrated in the fact that the study was conducted during the time period before the harvest, during a time of maximum food scarcity. As the instrument administered to assess food insecurity was based upon the caregiver's perception and experience of food scarcity, further examination of food availability in the home through dietary recall would be useful.

It is notable that there was no difference seen in anthropometric measurements in the enrolled children by food insecurity severity. While overt clinical signs of nutritional deficiency may not be evident in these children, lack of access to proper nutrition at all times threatens their optimal growth and development ${ }^{(36)}$. There are several explanations for this finding. First, adults in the home tend to prioritize food distribution to the most vulnerable and children are often protected from hunger related to food insecurity. Our sample also included young infants who were likely to have benefited from prolonged breast-feeding, known to protect against malnutrition in poor populations, and this may have reduced any observed differences in our study population. Also, there may be a communal sharing of resources among various households in this community. Children who live in the most severely food-insecure households may have normal anthropometric measurements if they are sent to the neighbour's or another family member's house for meals and other food resources. Despite these factors, our results corroborate previously published observations on the disassociation between anthropometrics and perceptions of food insecurity in Honduras and argue for more accurate indicators of food insecurity than anthropometric data, at least among children ${ }^{(16)}$.
There are limitations in our study that should be considered. We excluded caregivers younger than 16 years old and children who had $Z$-scores $<-2$ for weight/ length-for-age, leading to potential bias in our results. Without the age exclusion we may have found a different relationship between caregiver age and food insecurity. Further, we may have excluded children based on their anthropometric measurements who were most severely affected by food insecurity. We also did not assess other sociodemographic factors, such as income, and this is a limitation considering that poverty has a direct relationship to the likelihood of being food insecure ${ }^{(37,38)}$.

Despite these limitations, there are strengths to the present study. First, the span of time over which our baseline data were collected - two months - limits the potential influence of seasonality in our results on these data. In addition, since the study was conducted in one of the poorest areas of Honduras, our findings can be used to supplement community-based interventions targeting those areas most likely to be heavily affected by food insecurity. Finally, while the instrument used in the study was developed using an urban sample, it was validated in a similar cultural setting as our sample. It is possible that rural families have unique experiences in coping with food insecurity that are not captured in the current instrument such as reliance on monetary remittances or community sharing of food resources. Further research should use validation techniques to develop a food insecurity instrument specific for this rural context in Honduras.

\section{Conclusion}

Food insecurity is known to negatively impact child nutrition, health status and overall development. As such, awareness of factors that are associated with food insecurity will help to target those households most at risk for food insecurity as well as focus policy recommendations and public health interventions on modifying factors that may help decrease the burden of suffering. The present study illustrated the high prevalence of food insecurity in a rural Honduran population and that household food security was associated with maternal educational attainment but not child anthropometrics. These results indicate that public health programmes focusing on increasing educational opportunities for women would have a significant impact on food insecurity and therefore on child health in Honduras.

\section{Acknowledgements}

Sources of funding: This project has been supported by The Mathile Institute for the Advancement of Human Nutrition (Dayton, OH, USA), which had no role in the design, analysis or writing of this article. This research was also supported by a Health Resources and Services 
Administration (HRSA) Training Grant (no. T32-14001-24 to M.E.B.-D.), which had no role in the design, analysis or writing of this article. Conflicts of interest: No author has any conflicts of interest to disclose. Authors' contributions: M.E.B.-D., Y.E.d.C., M.E.B. and A.M.S.-R. designed the research; M.E.B.-D., Y.E.d.C., M.E.B. and A.M.S.-R. conducted the research; M.E.B.-D. and A.K. performed the statistical analysis; M.E.B.-D. and A.K. wrote the paper; M.E.B.-D. had primary responsibility for final content. All authors have read and approved the final manuscript.

\section{References}

1. Maxwell S \& Frankenberger TR (1992) Household Food Security: Concepts, Indicators, Measurements. New York: UNICEF/International Fund for Agricultural Development.

2. Campbell CC (1991) Food insecurity: a nutritional outcome or a predictor variable? J Nutr 121, 408-415.

3. Park K, Kersey M, Geppert J et al. (2009) Household food insecurity is a risk factor for iron-deficiency anaemia in a multi-ethnic, low-income sample of infants and toddlers. Public Health Nutr 12, 2120-2128.

4. Reis M (2012) Food insecurity and the relationship between household income and children's health and nutrition in Brazil. Health Econ 21, 405-427.

5. Saha KK, Tofail F, Frongillo EA et al. (2010) Household food security is associated with early childhood language development: results from a longitudinal study in rural Bangladesh. Child Care Health Dev 36, 309-316.

6. Belachew T, Hadley C, Lindstrom D et al. (2011) Food insecurity, school absenteeism and educational attainment of adolescents in Jimma Zone Southwest Ethiopia: a longitudinal study. Nutr J 10, 29.

7. Cook JT, Frank DA, Berkowitz C et al. (2004) Food insecurity is associated with adverse health outcomes among human infants and toddlers. J Nutr 134, 1432-1438.

8. Casey PH, Szeto KL, Robbins JM et al. (2005) Child healthrelated quality of life and household food security. Arch Pediatr Adolesc Med 159, 51-56.

9. The World Bank, Development Research Group (2012) World Development Indicators. http://data.worldbank.org/ country/honduras (accessed June 2012).

10. Webb P (2010) Medium- to long-run implications of high food prices for global nutrition. J Nutr 140, 143S-147S.

11. Food and Agriculture Organization of the United Nations \& World Health Organization (1992) Final Report of the International Conference on Nutrition. Rome/Geneva: $\mathrm{FAO} / \mathrm{WHO}$

12. Feleke ST, Kilmer RL \& Gladwin CH (2005) Determinants of food security in Southern Ethiopia at the household level. Agric Econ 33, 351-363.

13. Regassa N \& Stoecker BJ (2012) Household food insecurity and hunger among households in Sidama district, southern Ethiopia. Public Health Nutr 15, 1276-1283.

14. Tsai AC, Bangsberg DR, Frongillo EA et al. (2012) Food insecurity, depression and the modifying role of social support among people living with HIV/AIDS in rural Uganda. Soc Sci Med 74, 2012-2019.

15. David V, Moncada M \& Ordonez F (2004) Private and public determinants of child nutrition in Nicaragua and Western Honduras. Econ Hum Biol 2, 457-488.

16. Gray VB, Cossman JS \& Powers EL (2006) Stunted growth is associated with physical indicators of malnutrition but not food insecurity among rural school children in Honduras. Nutr Res 26, 549-555.
17. de Haen H, Klasen S \& Qaim M (2011) What do we really know? Metrics for food insecurity and undernutrition. Food Policy 36, 760-769.

18. Merten S \& Haller T (2009) Whose logic? The local redistribution of food aid targeting old and chronically sick people in Zambia. Hum Organ 68, 89-102.

19. Pelletier DL (2005) The science and politics of targeting: who gets what, when, and how. J Nutr 135, 890-893.

20. Black RE, Allen LH, Bhutta ZA et al. (2008) Maternal and child undernutrition: global and regional exposures and health consequences. Lancet 371, 243-260.

21. Black RE, Morris SS \& Bryce J (2003) Where and why are 10 million children dying every year? Lancet 361, 2226-2234.

22. Central Intelligence Agency (2012) Honduras. In The World Factbook. Washington, DC: CIA.

23. Acción contra el Hambre (2010) Situación de Seguridad Alimentaria y Nutricional en el Corredor Seco de Centroamérica. Análisis de casos en Guatemala, Honduras, Nicaragua. http://www.accioncontraelhambre.org/files/file/ informes/Corredor_Seco.pdf (accessed June 2012).

24. Programa de las Naciones Unidas para el Desarrollo (2012) Honduras. http://www.hn.undp.org/honduras/es/home.html (accessed March 2013)

25. Secretaria de Salud, Instituto Nacional de Estadística \& Macro International (2006) Encuesta Nacional de Demografia y Salud 2005-2006. Tegucigalpa, Honduras: SS, INE and Macro International.

26. Gonzalez W, Jimenez A, Madrigal G et al. (2008) Development and validation of measure of household food insecurity in urban Costa Rica confirms proposed generic questionnaire. J Nutr 138, 587-592.

27. de Onis M, Martorell R, Garza C et al. (2006) WHO child growth standards based on length/height, weight and age. Acta Paediatr 95, 76-85.

28. Sparks CS (2011) Parental investment and socioeconomic status influences on children's height in Honduras: an analysis of national data. Am J Hum Biol 23, 80-88.

29. Augustine JM, Cavanagh SE \& Crosnoe R (2009) Maternal education, early child care and the reproduction of advantage. Soc Forces $\mathbf{8 8}, 1-29$.

30. United Nations (2013) Millennium Development Goals 2015. http://www.un.org/millenniumgoals/bkgd.shtml (accessed January 2013).

31. Hackett M, Melgar-Quinonez H, Taylor CA et al. (2010) Factors associated with household food security of participants of the MANA food supplement program in Colombia. Arch Latinoam Nutr 60, 42-47.

32. Hanson KL, Sobal J \& Frongillo EA (2007) Gender and marital status clarify associations between food insecurity and body weight. J Nutr 137, 1460-1465.

33. Isanaka S, Mora-Plazas M, Lopez-Arana S et al. (2007) Food insecurity is highly prevalent and predicts underweight but not overweight in adults and school children from Bogota, Colombia. J Nutr 137, 2747-2755.

34. Nagata JM, Magerenge RO, Young SL et al. (2012) Social determinants, lived experiences, and consequences of household food insecurity among persons living with HIV/AIDS on the shore of Lake Victoria, Kenya. Aids Care 24, 728-736.

35. Anton JI (2010) The impact of remittances on nutritional status of children in Ecuador. Int Migr Rev 44, 269-299.

36. Hernandez DC \& Jacknowitz A (2009) Transient, but not persistent, adult food insecurity influences toddler development. J Nutr 139, 1517-1524.

37. Smith LC, El Obeid AE \& Jensen HH (2000) The geography and causes of food insecurity in developing countries. Agric Econ 22, 199-215.

38. Tarasuk VS (2001) Household food insecurity with hunger is associated with women's food intakes, health and household circumstances. J Nutr 131, 2670-2676. 